\title{
Improvement of Dimensional Stability of Acacia mangium Wood by Heat Treatment: A Case Study of Vietnam
}

\author{
Tran Van Chu* \\ Department of Wood Processing, Forestry University of Vietnam, Xuan Mai Town, Chwong My Distric, Hanoi, Vietnam
}

\begin{abstract}
Fast-grown wood generally contains a high proportion of juvenile wood that results in inferior dimensional stability and durability against biological deteriorations. In the present research, the Acacia mangium wood from plantation forests in Vietnam was treated with high temperature in air. The effects of heat treatment on physical properties of Acacia mangium wood, including mass loss (ML), water absorption (WA), water-repellent effectiveness (WRE) and anti-swelling efficiency (ASE) were examined. The results showed that the dimensional stability and the water-repellent effectiveness are increased by about $15-46 \%$ and $8-18 \%$, respectively. However, the mass and dimension of wood are decreased. The results also indicated that both treatment temperature and treatment duration significantly affect the wood properties of Acacia mangium. It is thus concluded that heat treatment demonstrates an interesting potential to improve the wood quality of Acacia mangium for solid timber products. This technology provides an environmentally safe method of protecting sustainable common woods to give a new generation of value-added biomaterials with increased stability without the use of toxic chemicals.
\end{abstract}

Key Words: Acacia mangium, anti-swelling efficiency (ASE), heat treatment, water-repellent effectiveness (WRE), Vietnam

\section{Introduction}

Wood is a natural polymer composite, mainly composed of cellulose, hemicellulose, lignin and extractives. It is the most versatile material and widely used for structural engineering indoor and outdoor applications. Wood holds an impressive range of attractive properties such as aesthetic appeal, easy workability, desirable strength to weight ratio, low thermal expansion (Desch and Dinwoodie 1996; Hon 2001). Nevertheless, wood also possesses some inherent drawbacks coming from dimensional instability under moisture content fluctuation, changes in appearance when exposed to weathering, and susceptibility to biological attack. These properties restrict the potential end-uses of wood (Hill 2006; Deka et al. 2007).

Acacia mangium is one of the most widely used fast growing tree species in plantation forestry programmes throughout Asia and the Pacific. Its desirable properties include rapid growth, good wood quality and tolerance of a wide range of soils and environments (Krisnawati et al. 2011). In recent years, it has been widely planted in many regions in Vietnam, from the North to the South. Acacia mangium wood is a hard wood and often used at the age of 6-8 year old. With the medium density (from $0.45-0.55 \mathrm{~g} / \mathrm{cm}^{3}$ ), Acacia mangium wood is mainly used for making pulp and paper, wood-based panels (particle board, fiberboard, ply-

Received: April 4, 2013. Revised: May 2, 2013. Accepted: May 5, 2013. 
wood, etc.), and furniture. However, like other fast growing wood, Acacia mangium wood possesses some disadvantages such as a high proportion of juvenile wood, low dimensional stability, vulnerable to fungi and insect damages, easy color change, etc. These drawbacks result in difficulties in the production and reduce the quality of the products.

In order to restrict these disadvantages and prolong the service life of wood and wood-based products, it is necessary to slow down the natural degradation process as much as possible. The traditional methods have focused on wood preservatives which are effective in improving durability of wood. However it is revealed that conventional preservatives contain some biocides resulting in environmental concerns (Militz et al. 1997). Wood modification is a new approach to overcome one or more disadvantages of wood through application of a process that alters the properties of the material. The aim of a modification is to reduce water absorption, improve dimensional stability, increase biological resistance, and enhance weathering performance of wood (Rowell 2006). As defined by Hill (2006), wood modification involves the action of a chemical, biological or physical agent on the material, and the modified wood should be nontoxic under service condition. Depending on applied agents, wood modification methods have been classified as thermal modification (or heat treatment), surface modification, impregnation modification, chemical modification and enzyme modification. Heat treatment is an environmentally friendly method used to reduce equilibrium moisture content (EMC) and water uptake of wood, improve dimensional stability (Kamdem et al. 2002; Kocaefe et al. 2008), increase biological durability, and therefore enhance wood quality, prolong service life of the wood products. More recently, heat treatment of wood has become a well established procedure, and there are a growing number of industrial treatment centers in various countries in Europe, for example Plato Wood in the Netherlands, Thermo Wood in Finland, Rectification and Le Bois Perdure in France. Several wood species are used for heat treatment, with different process conditions, depending on the species and the end-uses of the product. All of these processes use sawn wood and treatment temperatures between $160^{\circ} \mathrm{C}$ and $260^{\circ} \mathrm{C}$, but they differ in terms of process condition, such as the presence of a protective gas e.g. nitrogen, steam, dry processes or use of oils (Esteves and Pereira
2009).

During the heat treatment process, the organic acid coming from hemicelluloses creates an acidic environment which is combined with high temperature to break down the lignin-polysaccharide linkages in the wood structure, and makes wood from a hygroscopic material become a hydrophobic material (Kosikova et al. 1999; Wikberg and Maunu 2004). Hygroscopic property of wood after the heat treatment is closely related to changes in the chemical composition of wood, especially hemicelluloses and crystallization in wood. Water absorption of the wood after the heat treatment is reduced because a large number of hydroxyl groups (-OH) of the carbon-hydrogen compounds decreas (Nakano and Miyazaki 2003). Tuong and Li (2011) examine the change of chemical structure and some properties of Acacia hybrid wood after the heat treatment processes in an $\mathrm{N} 2$ gas protection environment with a treated temperature of from $210^{\circ} \mathrm{C}$ to $230^{\circ} \mathrm{C}$, the results showed that, after the heat treatment, a certain amount of hydroxyl groups in the Acacia hybrid is decreased, along with the reduction of hygroscopic property and the improvement of dimensional stability of the wood. Chuong (2011) investigates the influence of hydrothermal treatment technology on the physical properties of Acacia Auriculiformis, the results showed that the temperature and time of the treatment have a very clear impact on the density, water repellent efficiency and anti-swelling of the treated wood. Specifically, the wood density decreases but the dimensional stability improves through the analysis of water uptake and volume swelling of the treated wood.

This study was conducted to elucidate the improvement of dimensional stability of Acacia mangium wood planted in Ha Giang province, Vietnam by heat treatment technology in the normal air environment in order to determine the effect of the temperature and time of the heat treatment process to dimension loss. This includes the volume loss (DL) and mass loss (ML) of the wood samples after the treatment in comparison with the oven-dried wood samples before the treatment. The study also assessed the hydrophobic properties of the heat treated Acacia mangium wood to determine the water uptake (WA) and from that to calculate the water repellent efficiency (WRE) of the treated wood in order to evaluate the efficiency of the heat treatment on the hydrophilic property of Acacia mangium wood. 


\section{Materials and Methods}

The wood of Acacia mangium plantation forests in $\mathrm{Ha}$ Giang province, Vietnam at the age of 9-10 years and the average diameter of $18 \mathrm{~cm}$ was collected. The detail of the experimental procedure is described as follows.

\section{Sample preparation}

Samples were taken in accordance with the principles of the International Standards ISO 1975 about requirements and methods to test the mechanical and physical properties of wood, the number of replications is 10 for each experiment.

\section{Heat treatment method for wood}

High-temperature treatment in the air environment are used as shown in Fig. 1.

The parameters of the heat treatment processes are as follows: The initial moisture content of the wood material was from $15-18 \%$. The processing environment was the normal air. The initial processing time (heating and drying) was $6 \mathrm{~h}$. The initial processing temperature was $110^{\circ} \mathrm{C}$. During the heat treatment processes, the temperature was changed at five levels: $170^{\circ} \mathrm{C}, 180^{\circ} \mathrm{C}, 190^{\circ} \mathrm{C}, 200^{\circ} \mathrm{C}$ and $210^{\circ} \mathrm{C}$. The duration of maintaining maximum temperature during the heat treatment was changed at five levels: $2 \mathrm{~h}, 4 \mathrm{~h}, 6 \mathrm{~h}, 8 \mathrm{~h}$ and $10 \mathrm{~h}$. These were conducted at the lab center of the Wood Technology Faculty, Vietnam Forest University with the PLC control system of the maximum temperature of $230^{\circ} \mathrm{C}$ (Fig. 1).

\section{The heat treatment processes}

(1) The heating phase: the speed of increasing temper-

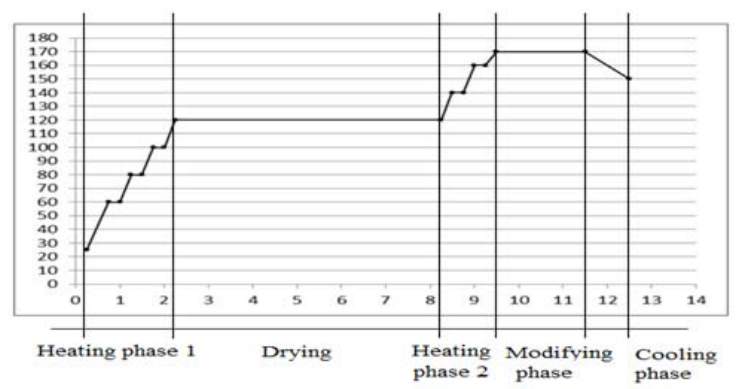

Fig. 1. Technological diagram of heat treatment process for Acacia mangium wood. ature was constant, so that the difference of temperature between the wood samples and the processing environment was not exceeding $30^{\circ} \mathrm{C}$ in order to limit the defects occurred during the processing.

(2) The drying phase: the selected temperature for this period was $110^{\circ} \mathrm{C}$, and maintained for $6 \mathrm{~h}$;

(3) Modifying phase: this is to reduce the number of experiments, but still meeting the basic requirements of mathematical statistics, the experiments were arranged in orthogonal experimental planning method, the temperature and processing time of the different processes were designed and shown in Table 1 and Table 2.

(4) The cooling phase: after the heat treatment process, the difference of temperature between the wood samples and the outside environment is high, in order to limit wood's defects after the processing, after the modifying phase, it is necessary to cool the wood samples gradually in the processing environment until their temperature is equivalent to the external environment, then the samples can be taken out for the next experiments.

The wood samples without any treatment were used as the control.

Table 1. The levels and steps changed in the experiment parameters

\begin{tabular}{lrrrrrrr}
\hline & \multicolumn{5}{c}{ The levels of experiment } \\
\cline { 2 - 5 } & $-\mathrm{c}$ & - & 0 & + & $+\mathrm{a}$ & \\
\cline { 2 - 6 } Experiment parameters & & & & \\
& 170 & 180 & 190 & 200 & 210 & 10 \\
Temperature $\left(\mathrm{T},{ }^{\circ} \mathrm{C}\right)$ & 2 & 4 & 6 & 8 & 10 & 2 \\
$\begin{array}{l}\text { Duration of maintained } \\
\text { maximum temperature }(\mathrm{h})\end{array}$ & & & & & & \\
\hline
\end{tabular}

Table 2. Experimental parameters of two factors

\begin{tabular}{ccccc}
\hline $\begin{array}{c}\text { Experiment } \\
\text { code }\end{array}$ & $\mathrm{X}_{1}$ & $\mathrm{X}_{2}$ & $\mathrm{~T}$ & $\mathrm{t}$ \\
\hline HT1 & - & - & 180 & 4 \\
HT2 & + & - & 200 & 4 \\
HT3 & - & + & 180 & 8 \\
HT4 & + & + & 200 & 8 \\
HT5 & $+a$ & 0 & 210 & 6 \\
HT6 & $-a$ & 0 & 170 & 6 \\
HT7 & 0 & $+a$ & 190 & 10 \\
HT8 & 0 & $-a$ & 190 & 2 \\
HT9 & 0 & 0 & 190 & 6 \\
\hline
\end{tabular}




\section{The main tested properties}

Before conducting the tests, the above heat treated samples were conditioned in a $20^{\circ} \mathrm{C}$ and $65 \% \mathrm{RH}$ (relative humidity) climate chamber for 2 weeks. The following properties were tested:

Mass loss of the heat treated samples (ML): the percentage of the weight of the sample after drying phase (oven-dried weight) compared to that of the sample after the heat treatment, and calculated as in formula 1 :

$$
M L=\frac{m_{\circ}-m_{\boldsymbol{h} t}}{m_{\odot}} \times 100(\%)
$$

where ML is the mass loss of the wood due to heat treatment processing $(\%) ; \mathrm{m}_{\mathrm{o}}$ is the weight of the sample after drying phase (oven-drying weight) $(\mathrm{g})$; $\mathrm{m}_{\mathrm{ht}}$ is the weight of the sample after heat treatment $(\mathrm{g})$.

Dimension loss of the heat treated samples (DL): the percentage of the volume of the sample after drying phase (oven-dried volume) compared to that of the sample after the heat treatment, and evaluated as in formula 2:

$$
D L=\frac{V_{o}-V_{h t}}{V_{o}} \times 100(\%)
$$

where DL is the dimension loss of the wood due to heat treatment (\%); $\mathrm{V}_{\mathrm{o}}$ is the volume of the sample after drying phase $\left(\mathrm{mm}^{3}\right) ; V_{\mathrm{ht}}$ is the volume of the sample after heat treatment $\left(\mathrm{mm}^{3}\right)$.

Water repellent efficiency (WRE) and water uptake (WA):

Based on Rowell (2005), the experimental method to determine the water uptake and the water repellent efficiency are: the control wood sample and the heat treated sample were oven-dried, then soaked in water at ambient temperature for 30-day period. During the soaking process, the water uptake was evaluated after each immersion time of 2 hours, 1 day, 2 days, 4 days, 8 days, 12 days, 20 days and 30 days. The water repellent efficiency was determined as in formula 3 :

$$
W R E=\frac{W A_{h t}-W A_{\text {d } c}}{W A_{\text {d } c}} \times 100(\%)
$$

where $\mathrm{WA}_{\mathrm{ht}}$ and $\mathrm{WA}_{\mathrm{dc}}$ are the water uptake of the treated sample and the control sample, respectively. The water uptake was calculated as in formula 4 :

$$
W A=\frac{W_{2}-W_{1}}{W_{1}} \times 100(\%)
$$

where $\mathrm{W}_{2}$ and $\mathrm{W}_{1}$ are, respectively, the weight of the immersed sample and the oven-dried sample.

$$
\text { Anti-sreelling coefficient (ASE): }
$$

Anti-swelling coefficient was calculated as in formula 5 based on the dimensional changes of the control and the heat treated samples after 30 days of immersion:

$$
A S E=\frac{S_{0}-S_{h t}}{S_{0}} \times 100(\%)
$$

where $S_{o}$ and $S_{h t}$ are the volume swelling of the treated sample and the control sample, respectively. The volume swelling of the wood sample was calculated as in formula 6 :

$$
S=\frac{V_{w}-V_{o}}{V_{o}} \times 100(\%)
$$

Where $V_{w}$ and $V_{o}$ are respectively the volume of the immersed sample and the oven-dried sample.

\section{Results and Discussion}

\section{The change in weight and dimension of the Acacia mangium wood samples before and after the heat treatment}

The dimension loss (DL) and mass loss (ML) of the different heat treatment processes are shown in Fig. 2 and Fig. 3. These are because wood is a natural organic material; its main chemical components include cellulose, hemi-

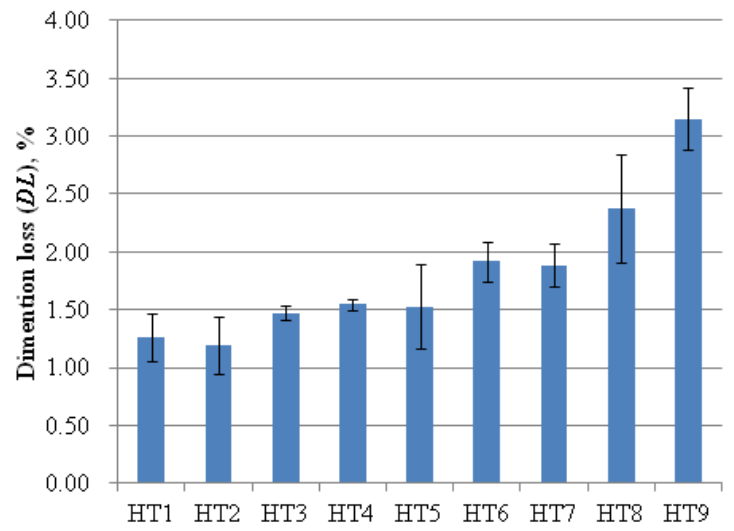

Fig. 2. DL of Acacia mangium wood after different heat treatment processes. 


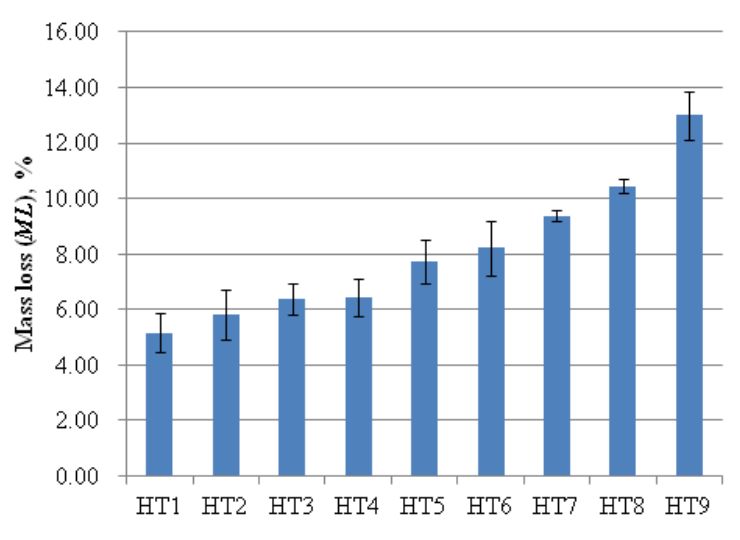

Fig. 3. ML of Acacia mangium wood after different heat treatment processes.

cellulose, lignin and extracts. During the heat treatment process, hemicellulose and a part of cellulose molecules in the amorphous regions are degraded due to high temperature (Esteves and Pereira 2009). This causes the chemical changes of the wood; or in other words, the basic components of the wood cell wall structure are changed in their number and dimension, leading to the reduction in dimension and weight of the wood after the heat treatment (Fig. 2).

Fig. 2 shows that the DL increases as temperature and time of the heat treatment increase. The highest dimension loss is about $3.15 \%$ when the wood is treated at the temperature of $210^{\circ} \mathrm{C}$ and the processing time of 6 hours. The lowest dimension loss is about $1.26 \%$ as the wood is processed at the temperature of $170^{\circ} \mathrm{C}$ and the processing time of 6 hours. Thus, the temperature and time of the treatment induce a significant influence on the dimensional change of the wood. These results provide a basis to determine the volume of wood loss due to heat treatment. The weight loss is one of the relatively important and meaningful factors in case the heat treatment technology is applied in large-scale production. Many studies demonstrate that the mass loss rate is an indicator to predict the quality of the wood after heat treatment (Stamm et al. 1946) (Fig. 3).

The results of ML in Fig. 3 show that the change in ML is basically similar to the change in DL. The ML rate increases as the intensity of the heat treatment or temperature and time increase. The reduction of wood mass due to heat treatment can be explained as follows. In the heat treatment process, under the effect of high temperature, a certain

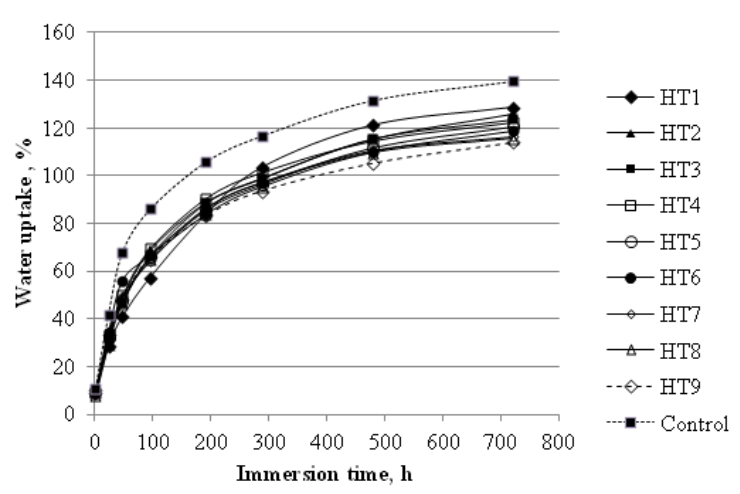

Fig. 4. WA of Acacia mangium wood after the different heat treatment processes.

amount of hemicellulose is degraded by heat, and produces acetic acid (Esteves and Pereira 2009). Acetic acid combines with water vapor from wood, and then makes wood become weak acid environment, this favors the hydrolysis reaction and the thermal release reaction to occur more intensely in hemicellulose and a part of cellulose in the amorphous regions. This results in a reduction in the amount of hemicellulose and cellulose, leading to a decrease in wood mass.

\section{Water uptake (WA) and water repellent efficiency (WRE) of the heat treated}

\section{Acacia mangium wood}

In the experiment, the wood samples were immersed in the water for 30 days, and evaluated the water uptake at different times. The results of the WA of the heat treated and the control Acacia mangium wood are presented in Fig. 4.

Fig. 4 shows that there is a significant difference of the WA between the heat treated wood and the control. At every time of the soaking, the WA of the treated sample is lower than that of the control sample.

To evaluate the efficiency of the heat treatment on the hydrophilic property of Acacia mangium wood, the WRE was calculated and presented in Fig. 5 which shows that prolonging the time and increasing the temperature of the heat treatment process bring out a reduction in water uptake of the wood. This is because the content of extracts is reduced due to high temperature and long treatment time. In addition, a very important component with the most hydrophilic ability in the wood, the free hydroxyl (-OH) groups, they 


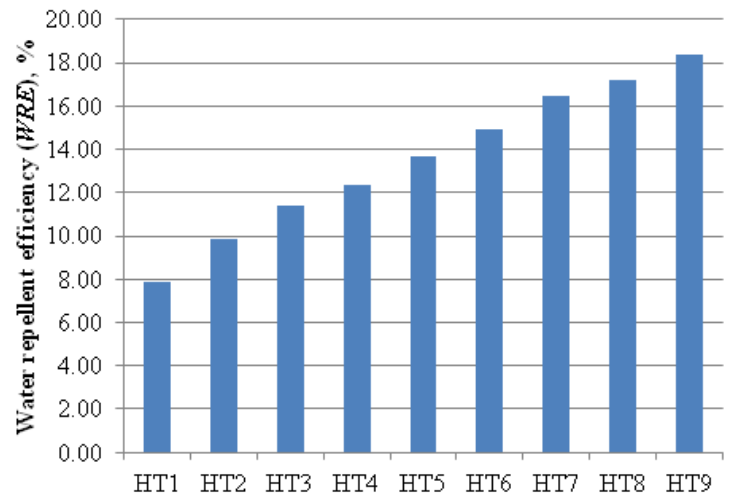

Fig. 5. The relationship between the heat treatment processes and WRE of Acacia mangium wood.

Table 3. VSR of the Acacia mangium wood samples at different heat treatment process

\begin{tabular}{ccccc}
\hline $\begin{array}{c}\text { Heat } \\
\text { treatment } \\
\text { process }\end{array}$ & $\begin{array}{c}\text { Temperature } \\
\left({ }^{\circ} \mathrm{C}\right)\end{array}$ & Time $(\mathrm{h})$ & WSR $(\%)$ & $\begin{array}{c}\text { Standard } \\
\text { deviation } \\
(\%)\end{array}$ \\
\hline Control & - & - & 13.49 & 0.51 \\
HT1 & 170 & 6 & 10.36 & 0.90 \\
HT2 & 180 & 4 & 9.42 & 1.01 \\
HT3 & 180 & 8 & 9.21 & 0.94 \\
HT4 & 190 & 2 & 8.85 & 0.71 \\
HT5 & 190 & 6 & 8.70 & 0.96 \\
HT6 & 190 & 10 & 8.49 & 0.79 \\
HT7 & 200 & 4 & 8.15 & 0.69 \\
HT8 & 200 & 8 & 7.91 & 0.82 \\
HT9 & 210 & 6 & 7.35 & 0.73 \\
\hline
\end{tabular}

are normally placed in the structure of cellulose and hemicellulose, during the heat treatment process, due to thermal release process, the hydrolysis reaction and the formation of cross-linking make the contents of hemicellulose and cellulose in the amorphous region decrease, resulting in a reduction of the number of free hydroxyl groups, therefore, the water uptake of the wood decreased, the water repellent efficiency increased. The reduction in the content of hydroxyl $(-\mathrm{OH})$ groups in the heat treated wood has been demonstrated in many studies (Nakano and Miyazaki 2003) (Fig. 5).

\section{Anti-swelling coefficient (ASE)}

Dimensional stability of wood is one of the important cri-

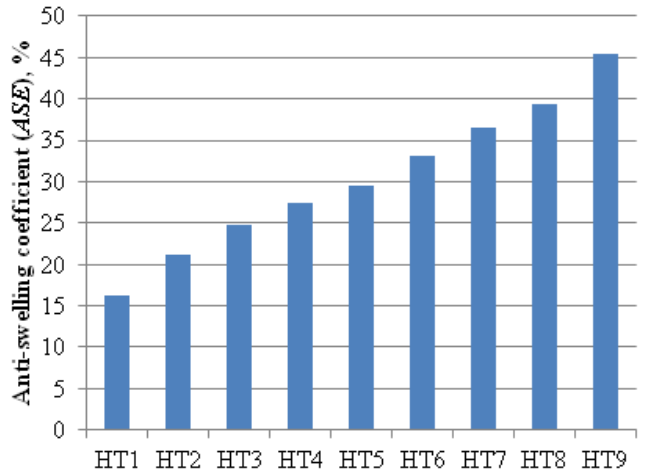

Fig. 6. The relationship between the heat treatment processes and WRE of Acacia mangium wood.

teria assessing the quality of wood, especially when wood is used in construction and architecture. In the study of wood modification, dimensional stability of wood is commonly assessed by anti-swelling coefficient (ASE). ASE is the rate of decrease in the volume of treated wood and untreated wood (control) (Rowell 2005). In this study, the volume swelling ratio (WSR) and ASE are determined on the wood samples after 30 days of soaking at room temperature. The results of VSR of the wood samples after 30 days of soaking are displayed in Table 3.

Table 3 shows that Acacia mangium wood planted in $\mathrm{Ha}$ Giang has relatively high VSR (13.49\%). After the heat treatment at different temperature and time, the VSR reduces significantly as shown in Fig. 6.

The ASE of the heat treated Acacia mangium wood increases as increasing temperature and prolonging time of the treatment. The research results are consistent with the results of the national/international studies in heat treated wood field.

\section{Conclusions}

From the above results, it can be concluded that the dimensional stability of Acacia mangium wood can be improved by applying thermal treatment technology. More specifically,

1. Applying heat treatment for Acacia mangium wood can reduce the water uptake by $8-18 \%$ in comparison to that of the control, the volume swelling of the treated wood is lower than the control by $15-46 \%$. However, the mass and vol- 
ume of the treated wood also reduce.

2. Applying heat treatment technology in the normal air environment can improve dimensional stability of planted Acacia mangium wood. However, high-temperature treatment often decreases mass and volume of the wood; therefore, it is recommended that further research efforts are needed to develop a reasonable heat treatment process which can reduce mass loss and dimension loss of the wood, but still maintains dimensional stability as requirements of the products.

\section{References}

Chuong PV. 2011. Influences of the hydro-thermal treatment on physical properties of Acacia auriculiformis wood. 2011 International Symposium on Comprehensive Utilization of Wood Based Resources. Zhejiang A\&F University, Lin'an, Zhejiang, pp 105-110.

Deka M, Tomažič M, Petrič M. 2007. Photo-degradation of modified and non-modified wood, coated with water borne acrylic coatings during artificial light exposure. Proceedings of the International Research Group on Wood Preservation. Document No: IRG/WP 07-30416.

Desch HE, Dinwoodie JM. 1996. Timber- Structure, Properties, Conversion and Use. McMillan Press Ltd, New York.

Esteves B, Pereira H. 2009. Wood modification by heat treatment: A review. BioResources 4: 370-404.

Hill CAS. 2006. Wood modification. Chemical, thermal and other processes. John Wiley \& Son Ltd, New York.

Hon DNS. 2001. Weathering and photochemistry of wood. In: Wood and cellulose chemistry (Hon DNS, Siraishi N, eds). Marcel Dekker, New York, pp 513-546.

ISO 1975. Wood - Sampling methods and general requirements for physical and mechanical tests, International organization for standardization Information Handling Services. International standard - ISO 3129-1975.

Kamdem DP, Pizzi A, Jermannaud A. 2002. Durability of heat-treated wood. European Journal of Wood and Wood Products 60: 1-6.

Kocaefe D, Shi JL, Yang DQ, Bouazara M. 2008. Mechanical properties, dimensional stability, and mold resistance of heat-treated jack pine and aspen. Forest Products Journal 58: 88-93.

Kosikova B, Hricovini M, Cosentino C. 1999. Interaction of lignin and polysaccharides in beech wood (Fagus sylvatica) during drying processes. Wood Science and Technology 33: 373-380.

Krisnawati H, Kallio M, Kanninen M. 2011. Acacia mangium Willd: Ecology, Silviculture and Productivity. CIFOR, Bogor, Indonesia.

Militz H, Beckers E PJ, Homan WJ. 1997. Modification of solid wood: research and practical potential. Proceedings of the International Research Group on Wood Preservation. Whistler, Canada Document No: IRG/WP 97-40098.

Nakano T, Miyazaki J. 2003. Surface Fractal dimensionality and hygroscopicity for heated wood. Holzforschung 57: 289-294.

Rowell RM. 2005. Chemical modification of wood. In: Handbook of wood chemistry and wood composites (Rowell RM, eds). CRC Press, New York, pp 210-250.

Rowell RM. 2006. Chemical modification of wood: A short review. Wood Material Science and Engineering 1:29-33.

Stamm A, Burr H, Kline A. 1946. A heat stabilized wood. Ind Eng Chem 38: 630-634.

Tuong VM, Li J. 2010. Effect of heat treatment on the change in color and dimensional stability of acacia hybrid wood. BioResources 5:1257-1267.

Tuong VM, Li J. 2011. Changes caused by heat treatment in chemical composition and some physical properties of acacia hybrid sapwood. Holzforschung 65:67-72.

Wikberg H, Liisa MS. 2004. Characterisation of thermally modified hard- and softwoods by ${ }^{13} \mathrm{C}$ CPMAS NMR. Carbohydrate Polymers 58: 461-466. 